\title{
Oxygen nonstoichiometry and transport properties of $\mathrm{LaNi}_{0.6} \mathrm{Co}_{0.4} \mathrm{O}_{3-\delta}$
}

\author{
$\underline{\text { R.A. Budiman }}^{\mathrm{a}^{*}}$, Y. Uzumaki ${ }^{\mathrm{a}}$, H. J. Hong ${ }^{\mathrm{a}}$, T. Miyazaki ${ }^{\mathrm{b}}$, S. Hashimoto ${ }^{\mathrm{a}}$, T. Nakamura ${ }^{\mathrm{c}}$, K.
} Yashiro $^{\text {a }}$ K. Amezawa ${ }^{\mathrm{c}}$, T. Kawada ${ }^{\mathrm{a}}$

${ }^{a}$ Graduate School of Environmental Studies, Tohoku University, 6-6-01 Aoba, Aramaki, Aobaku, Sendai 980-8579, Japan

${ }^{\mathrm{b}}$ School of Engineering, Tohoku University, 6-6-01 Aoba, Aramaki, Aoba-ku, Sendai 980-8579, Japan

'Institute Multidisciplinary Research of Advance Material, Tohoku University, 2-1-1 Katahira, Aoba-ku, Sendai, 980-8577, Japan

\section{*Corresponding author:}

Present address: National Institute of Advanced Industrial Science and Technology, Higashi, 11-1, AIST Tsukuba Central 5, Tsukuba, Ibaraki 305-8565, Japan

Email: budiman.riyan@aist.go.jp 


\begin{abstract}
The oxygen nonstoichiometry of the perovskite-type oxide, $\mathrm{LaNi}_{0.6} \mathrm{Co}_{0.4} \mathrm{O}_{3-\delta}$, was measured at various temperatures and oxygen partial pressures $\left(p\left(\mathrm{O}_{2}\right)\right)$ by high temperature gravimetry and coulometric titration. The oxygen nonstoichiometry appeared independent of $p\left(\mathrm{O}_{2}\right)$ in the range of $10^{-4}$ bar $>p\left(\mathrm{O}_{2}\right)$, which was in good agreement with the tendency of lattice parameter determined by the high-temperature X-ray diffraction (HT-XRD). The oxygen nonstoichiometry behaviour was analysed using the defect equilibrium model assuming delocalized electron. In addition, the diffusion coefficient, $D^{*}$, and the surface reaction rate constant, $k^{*}$, were obtained by the isotope exchange and secondary ion mass spectometry. The $D v$ estimated from the $D^{*}$ showed similarity with those reported for other perovskite oxide which supported the reliability of $\delta$ determined in this work.
\end{abstract}

Keywords: Oxygen nonstoichiometry, defect chemical, diffusion coefficient. 
1 Introduction

The relatively new cathode material, $\mathrm{La}(\mathrm{Ni}, \mathrm{Co}) \mathrm{O}_{3-\delta}$, is expected as one of the alternative cathode of SOFC. In this cathode, the $\mathrm{LaCoO}_{3-\delta}-\mathrm{LaNiO}_{3-\delta}$ solid solution has relatively high performance as the electrode. Generally, the B-site metal has a strong connection with the oxygen form $\mathrm{BO}_{6}$ octahedron. The local $\mathrm{BO}_{6}$ octahedron structure strongly affects the electronic structure around the conduction and valence band. When the B-site is substituted with transition metal, it may lead to a change in the strong connection of $\mathrm{BO}_{6}$ octahedron and the defect chemical properties are supposed to be complex [1]. The study of the defect structure is important since the defect structure explains how the oxygen vacancy is generated in the cathode.

So far, $\mathrm{La}(\mathrm{Ni}, \mathrm{Co}) \mathrm{O}_{3-\delta}$ series have been reported to have a high electrical conductivity (1300 $\mathrm{Scm}^{-1}$ at $\left.1073 \mathrm{~K}\right)[2,3]$. Moreover, the thermal expansion coefficient $\left(14-17 \times 10^{-6} \mathrm{~K}^{-1}\right)$ is tolerable for the use with oxide ion conducting electrolytes [3,4]. It can also be expected that a chromia tolerance of $\mathrm{La}(\mathrm{Ni}, \mathrm{Co}) \mathrm{O}_{3-\delta}$ is higher than the cathode materials with $\mathrm{Sr}$ in the composition. However, $\mathrm{LaNi}_{0.6} \mathrm{Co}_{0.4} \mathrm{O}_{3-8}$ react with $\mathrm{ZrO}_{2}$ from $\mathrm{YSZ}$ to form $\mathrm{La}_{2} \mathrm{Zr}_{2} \mathrm{O}_{7}$ which could decreases the electrode performance as reported by M. Hrovat [5].

Hjalmarsson et al. reported that $\mathrm{LaNi}_{0.6} \mathrm{Co}_{0.4} \mathrm{O}_{3-8}$ doesn't have an oxygen vacancy in the air up to $1273 \mathrm{~K}$ which is measured by thermogravimetry [4]. However, there is limited knowledge of $p\left(\mathrm{O}_{2}\right)$ dependence on the oxygen vacancy concentration and the defect chemistry on $\mathrm{LaNi}_{0.6} \mathrm{Co}_{0.4} \mathrm{O}_{3-\delta}$ so far. In this study, the oxygen nonstoichiometry of $\mathrm{LaNi}_{0.6} \mathrm{Co}_{0.4} \mathrm{O}_{3-\delta}$ has been evaluated under the controlled temperature and $p\left(\mathrm{O}_{2}\right)$ by high-temperature gravimetry and coloumetric titration. The oxygen nonstoichiometry of $\mathrm{LaNi}_{0.6} \mathrm{Co}_{0.4} \mathrm{O}_{3-\delta}$ was analyzed based on the defect equilibrium model of delocalized electron. In addition, high temperature $-\mathrm{X}$-ray diffraction (HT-XRD) measurement was performed to get a better understanding on the 
expansion of lattice parameter, as an effect of thermal and chemical expansions. The oxygen transport properties were also evaluated by the isotope exchange technique, which gave another important knowledge on how the $\mathrm{LaNi} .6 \mathrm{Co} 0.4 \mathrm{O}_{3-\delta}$ behave as a function of temperature and $p\left(\mathrm{O}_{2}\right)$.

\section{Experiments}

2.1 Sample preparation

Powder of $\mathrm{LaNi}_{0.6} \mathrm{Co}_{0.4 \mathrm{O}}$ - $\delta$ was synthesized by the Pechini method. A powder of thermallydehydrated $\mathrm{La}_{2} \mathrm{O}_{3}\left(99.99 \%\right.$, Rare Metallic co., Japan) and the solution of $\mathrm{Ni}\left(\mathrm{NO}_{3}\right)_{2} \cdot 6 \mathrm{H}_{2} \mathrm{O}$ (99.99\%, Kojundo Chemical Laboratory co., Japan), and $\mathrm{Co}\left(\mathrm{NO}_{3}\right)_{2} .6 \mathrm{H}_{2} \mathrm{O}(99.99 \%$, Kojundo Chemical Laboratory co., Japan) were mixed in $\mathrm{HNO}_{3}$ at a proper ratio. An amount of citric acid (5 times of total mole of the cation) and ethylene glycol (3 times of total mole of the cation) were added into the mixed solution. The mixed solutions were heated up to $473 \mathrm{~K}$ by the mantle heater and the obtained precursor was calcined in air at $1273 \mathrm{~K}$ for 8 hours. The crystal phase of $\mathrm{LaNi}_{0.6} \mathrm{Co}_{0.4 \mathrm{O}} \mathrm{O}_{3-\delta}$ was identified with an X-ray diffractometer (XRD) with $\mathrm{CuK} \alpha$-radiation, and the single phase of $\mathrm{LaNi}_{0.6} \mathrm{Co}_{0.4} \mathrm{O}_{3-\delta} \delta$ was confirmed.

\subsection{High-temperature gravimetry}

The 0.5 gram powder of $\mathrm{LaNi}_{0.6} \mathrm{Co}_{0.4} \mathrm{O}_{3-\delta}$ was pressed into a pellet at $2 \mathrm{MPa}$. The pellet samples were sintered at $1073 \mathrm{~K}$ for 6 hours. The oxygen nonstoichiometry was measured by the high-temperature gravimetry using electronic microbalances (Cahn D200, Thermo Fisher 
scientific). The pellet samples were placed into a silica basket, which is connected to the silicon wire that hanged onto the microbalancer. The sample and the counter balance were introduced to the same gas atmosphere to check the weight different on the sample. The measurements were finished at various temperatures $(873-1073 \mathrm{~K})$ and $p\left(\mathrm{O}_{2}\right)\left(1-10^{-3}\right.$ bar). The oxygen content variation was determined from the weight change by this equation:

$$
\Delta \delta=\frac{M_{S}}{M_{O}} \frac{\Delta w_{S}}{w_{s}}
$$

where $\Delta \delta, M_{s}, M_{o}$, and $w_{s}$ are the variation of oxygen nonstoichiometry, the formula weight of the sample and oxygen atom, and the weight of the sample, respectively. The absolute value of oxygen vacancy was calculated by the weight change from pure $\mathrm{O}_{2}$ to pure $\mathrm{H}_{2}$. The oxygen vacancywas taken when the sample weight and $p\left(\mathrm{O}_{2}\right)$ reached the stable values and the decomposition of $\mathrm{LaNi}_{0.6} \mathrm{Co}_{0.4} \mathrm{O}_{3-\delta}$ was completed. After the sample was decomposed in the dry $\mathrm{H}_{2}$ flow, the decomposition phase was identified by the XRD. The equation of the reduction process for $\mathrm{LaNi}_{0.6} \mathrm{Co}_{0.4} \mathrm{O}_{3-\delta}$ explained as follows:

$$
\mathrm{LaNi}_{0.6} \mathrm{Co}_{0.4} \mathrm{O}_{3-\delta} \rightarrow 0.5 \mathrm{La}_{2} \mathrm{O}_{3}+0.6 \mathrm{Ni}+0.4 \mathrm{Co}+(1.5-\delta) / 2 \mathrm{O}_{2}
$$

According to eq (2), one mole of $\mathrm{LaNi}_{0.6} \mathrm{Co}_{0.4} \mathrm{O}_{3-\delta}$ will emit (1.5- $\left.\delta\right) / 2$ mol of oxygen to gas phase.

\subsection{Coulometric titration}

For coulometric titration, the powder of $\mathrm{LaNi}_{0.6} \mathrm{Co}_{0.4} \mathrm{O}_{3-\delta}$ was pressed into a pellet and sintered at $1073 \mathrm{~K}$ for 6 hours. Yttria-stabilized zirconia (YSZ) tube was used as an electrolyte. The $\mathrm{LaNi}_{0.6} \mathrm{Co}_{0.4} \mathrm{O}_{3-\delta}$ powder of 0.5 gram was lumped into the inside of the tube and mechanically crushed and pressed in order to get contact with YSZ. The platinum paste was 
painted on the outside of the YSZ tube. The oxygen nonstoichiometry was determined by the electric charge which passed through into the cell as described by the equation:

$$
\Delta \delta=(C / F)\left(M_{s} / w_{s}\right)
$$

where $C, F, M_{s}$, and $w_{s}$ are the total amount of electric charge, Faraday constant, the formula weight of the sample, and the weight of the sample, respectively. The oxygen coulometric titration was carried out at different temperatures $(873-1073 \mathrm{~K})$. The $\mathrm{LaNi}_{0.6} \mathrm{Co}_{0.4} \mathrm{O}_{3-\delta} \delta$ was reduced by electrochemically "pumping-out" the oxygen by flowing charge into sample.

\subsection{Isotope exchange and secondary ion mass spectrometry}

Oxygen transport properties were evaluated using the bulk samples. The bulk samples were prepared by pressing the $\mathrm{LaNi}_{0.6} \mathrm{Co}_{0.4} \mathrm{O}_{3-\delta}$ powder and then sintering at $1573 \mathrm{~K}$. The relative density of the pellet sample was higher than $98 \%$. The surface of the pellet was polished with a diamond paste to get a fine surface. The polished sample was cut into pieces around $5 \mathrm{~mm} \times 3$ $\mathrm{mm}$ and $2 \mathrm{~mm}$ in thickness. Prior to isotope exchange treatment, the sample was pre-annealed at controlled temperature and $p\left(\mathrm{O}_{2}\right)$ for 3 hours. After the pre-annealing, the sample was placed into the alumina basket which was covered by platinum foil. The sample in the sample holder was placed into the glass chamber where the thermocouple (Pt/Pt-3\%Rh) was attached to the sample to monitor the temperature. 
After the sample was set in a chamber, it was heated up to the constant temperature at ${ }^{16} \mathrm{O}_{2}$ for 30 minutes before the gas was abruptly changed to the isotope enriched one $\left({ }^{18} \mathrm{O}_{2}, 99 \%\right.$ purity). The exchange time was varied with the exchange temperature. The time was 30,10 , and 5 minutes for $873 \mathrm{~K}, 973 \mathrm{~K}$, and $1073 \mathrm{~K}$, respectively. After the isotope exchange, the sample was quenched to the room temperature. Prior to secondary ion mass spectrometry (SIMS), the sample was cut to get the cross section surface and then polished by diamond solution to get a fine surface. The SIMS measurement (SIMS, CAMECA IMS-7F) was utilized to determine the diffusion profile of the samples. The $\mathrm{Cs}+(15 \mathrm{keV})$ was used as a primary ion beam of the SIMS. The line scanning mode was used where the point of measurement were taken from the edge of the sample up to $500 \mu \mathrm{m}$ with a primary ion beam of $0.5 \mathrm{nA}$. The negative ion signal of ${ }^{16} \mathrm{O}^{-}$and ${ }^{18} \mathrm{O}^{-}$were collected from the sputtered area.

\subsection{High-temperature X-ray diffractometer}

High-temperature X-ray diffractometer (D8 Discovery with LYNXEYE, Bruker AXS, and $\mathrm{CuK} \alpha$ radiation) was used for in-situ high-temperature x-ray diffraction (HT-XRD). The HTXRD measurement was utilized to determine the lattice parameter and the cell volume of LaNio.6 $\mathrm{Co} 0.4 \mathrm{O}_{3-\delta}$ in various $p\left(\mathrm{O}_{2}\right)\left(1-10^{-3}\right.$ bar $)$ and temperatures $(573-1073 \mathrm{~K})$. The LaNio.6 $\mathrm{Co}_{0.4} \mathrm{O}_{3-\delta}$ powder was set on a Pt-Rh heater inside the XRD chamber, for which the $p\left(\mathrm{O}_{2}\right)$ was monitored at the inlet and the outlet of the XRD chamber by two oxygen sensors. The measurement was taken at every $100 \mathrm{~K}$ with holding time of 2 hours for each temperature until the equilibrium condition was ensured. 


\section{Results and Discussion}

3.1 Oxygen nonstoichiometry and defect chemical model

The oxygen nonstoichiometry of $\mathrm{LaNi}_{0.6} \mathrm{Co}_{0.4} \mathrm{O}_{3-\delta}$ was measured by the high-temperature gravimetry and coulometric titration. The absolute value of $\mathrm{LaNi}_{0.6} \mathrm{Co}_{0.4} \mathrm{O}_{3-\delta}$ was determined by the decomposition of the sample in $\mathrm{H}_{2}$ atmosphere. Fig. 1 shows the XRD pattern for $\mathrm{LaNi}_{0.6} \mathrm{Co}_{0.4} \mathrm{O}_{3-\delta}$ before the thermogravimetry measurement and after the sample was decomposed by $\mathrm{H}_{2}$ at $973 \mathrm{~K}$. All the peaks after the decomposition were assigned to $\mathrm{Ni}$, Co, $\mathrm{La}_{2} \mathrm{O}_{3}$ and small amount of $\mathrm{La}(\mathrm{OH})_{3}$. Considering the thermodynamic stability of $\mathrm{La}(\mathrm{OH})_{3}$ at $973 \mathrm{~K}$, it was most likely formed after cooling the sample. Thus, the absolute value of oxygen content was calculated using equation:

$$
\delta_{i}=1.5-\left(\frac{m_{i}-g}{g}\right)\left(\frac{0.5 M\left(\mathrm{La}_{2} \mathrm{O}_{3}\right)+0.6 M(\mathrm{Ni})+0.4 M(\mathrm{Co})}{M(0)}\right)
$$

Where $m_{i}$ and $g$ are the mass of the sample before and after the decomposition, respectively. The $M\left(\mathrm{La}_{2} \mathrm{O}_{3}\right), M(\mathrm{Ni}), M(\mathrm{Co})$, and $M(\mathrm{O})$ are the molar mass of $\mathrm{La}_{2} \mathrm{O}_{3}, \mathrm{Ni}, \mathrm{Co}$, and Oxygen, respectively.

Figure 2 shows the oxygen nonstoichiometry of $\mathrm{LaNi}_{0.6} \mathrm{Co}_{0.4} \mathrm{O}_{3-\delta}$ at the intermediate temperature of $873 \mathrm{~K}$ to $1073 \mathrm{~K}$ and the $p\left(\mathrm{O}_{2}\right)$ range between 1 bar to $10^{-10}$ bar. Closed and open symbols show the data points measured by high-temperature gravimetry and coulometric titration, respectively. The results of high-temperature gravimetry and coulometric titration show 
good agreement. The oxygen vacancy concentration, $\delta$, shows the minimum value (close to 0 ) at the stoichiometric composition in the range $10^{-4}$ bar $>p\left(\mathrm{O}_{2}\right)$, where the oxidation state of nickel and cobalt are estimated to be $3^{+}$. With further reduction of $p\left(\mathrm{O}_{2}\right)$, the oxygen content decreased and the abrupt changes of oxygen content occurred during decomposition at $p\left(\mathrm{O}_{2}\right)$ shown by vertical lines in Fig. 2, indicating that the sample began to decompose and second phase emerged, as shown in Fig. 1.

In this study, the defect equilibrium of $\mathrm{LaNi}_{0.6} \mathrm{Co}_{0.4} \mathrm{O}_{3-\delta}$ with gas phase can be described as:

$$
\frac{1}{2} \mathrm{O}_{2}^{\text {gas }}+V_{\mathrm{O}}+2 e^{-}=\mathrm{O}_{\mathrm{O}}^{x}
$$

where $V_{0}, e^{-}$, and $\mathrm{O}_{\mathrm{O}}^{x}$ are oxygen vacancy, electron, and oxygen in the lattice, respectively. The relative chemical potential of monatomic oxygen atom, $\mu_{\mathrm{O}}-\mu_{\mathrm{O}}^{0}$, in the equilibrium with gas at a certain oxygen partial pressure is written by [6]:

$$
\mu_{\mathrm{O}}-\mu_{\mathrm{O}}^{0}=\frac{R T}{2} \ln p\left(\mathrm{O}_{2}\right)
$$

Where $\mu_{\mathrm{O}}^{0}$ is the oxygen potential in equilibrium with 1 bar of oxygen. From the Gibbs Helmholtz equation, the partial molar enthalpy of oxygen, $h_{\mathrm{O}}-h_{\mathrm{O}}^{0}$, and partial molar entropy of oxygen, $s_{0}-s_{0}^{0}$, can be calculated by

$$
\begin{array}{r}
h_{\mathrm{O}}-h_{\mathrm{O}}^{0}=\frac{\partial}{\partial\left(\frac{1}{T}\right)}\left(\frac{R}{2} \ln p\left(\mathrm{O}_{2}\right)\right) \\
s_{\mathrm{O}}-s_{\mathrm{O}}^{0}=-\frac{\partial}{\partial(T)}\left(\frac{R T}{2} \ln p\left(\mathrm{O}_{2}\right)\right)
\end{array}
$$

where the $h_{0}^{0}$ and $s_{0}^{0}$ are partial molar of enthalpy and entropy, respectively, in equilibrium with 1 bar of oxygen. $R / 2 \ln p \mathrm{O}_{2}$ and $R T / 2 \ln p \mathrm{O}_{2}$ were obtained by interpolation of the oxygen nonstoichiometry data as a function of $\delta$. From the slopes of $\frac{R}{2} \ln p\left(\mathrm{O}_{2}\right)$ vs. $1 / T$ plots and $\frac{R T}{2} \ln p\left(\mathrm{O}_{2}\right)$ vs. $T, h_{\mathrm{O}}-h_{\mathrm{O}}^{0}$ and $s_{\mathrm{O}}-s_{\mathrm{O}}^{0}$ were obtained as a function of $\delta$. 
In order to explain the oxygen nonstoichiometry behavior of $\mathrm{LaNi}_{0.6} \mathrm{Co}_{0.4} \mathrm{O}_{3-\delta}$, the defect equilibrium model with delocalized electron is applied in this study because the conduction mechanism was confirmed to be a metallic conduction $[2,3]$. The delocalized model which was developed by Mizusaki et al. is described by the equation:

$$
\frac{R T}{2} \ln p\left(\mathrm{O}_{2}\right)=\Delta h_{O}^{0}(x)-a(x) \delta-T\left(\Delta s_{O}^{0}(x)+R \ln \left(\frac{\delta}{(3-\delta)}\right)\right)
$$

where the $\Delta h_{O}^{0}(x)$ and $\Delta s_{O}^{0}(x)$ are standard partial molar enthalpy and entropy changes of oxygen, respectively. Mizusaki et al. determined $h_{\mathrm{O}}-h_{0}^{0}$ and $s_{\mathrm{O}}-s_{\mathrm{O}}^{0}$ are independent of temperature. They described $h_{\mathrm{O}}-h_{\mathrm{O}}^{0}$ by linear function of $\delta$ with constant term of $h_{\mathrm{O}}-h_{\mathrm{O}}^{0}$ and $a(x)$. In this study, the $\mathrm{x}$ is the $\mathrm{Ni}$ content in $\mathrm{LaNi}_{0.6} \mathrm{Co}_{0.4} \mathrm{O}_{3-\delta}$. The $a(x)$ parameter appeared to be the deviation from the ideal solution model and the additional change in enthalpy was attributed to interaction among defects and lattice ions [7-10]. In the case of partial molar entropy, $s_{0}-s_{0}^{0}$, only configurational entropy change of oxygen vacancy is considered. The partial molar enthalpy and entropy is described by this equation:

$$
\begin{aligned}
& h_{\mathrm{O}}-h_{\mathrm{O}}^{0}=\Delta h_{O}^{0}(x)-a(x) \delta \\
& s_{\mathrm{O}}-s_{\mathrm{O}}^{0}=\Delta s_{O}^{0}(x)+R \ln \left(\frac{\delta}{(3-\delta)}\right)
\end{aligned}
$$

The plot of partial molar enthalpy and entropy is shown by Fig. 3. The fitting parameter for this model is $-150(\mathrm{~J} / \mathrm{mol} \mathrm{K}),-230(\mathrm{~kJ} / \mathrm{mol})$, and $50(\mathrm{~kJ} / \mathrm{mol})$ for $\Delta s_{O}^{0}(x), \Delta h_{O}^{0}(x)$, and $a(\mathrm{x})$, respectively. The dash lines in Fig. 3 are the delocalized model fitted to the experimental data.

The model in this case appears to be in good agreement with the experimental data as shown in Fig. 2. However, significant deviations are observed in the partial molar enthalpy and entropy when $\delta$ approaches zero. It is because the experimental determination of the absolute value of $\delta$ by the decomposition method gave a non-zero $\delta$ values $(0.0003$ at $1073 \mathrm{~K})$ at the high 
oxygen partial pressure limit of the nonstoichiometry isotherm shown in the plateau in Fig.2. Since the possible error range for the determination of absolute $\delta$ is around 0.0001 , it is difficult to judge the validity of those values only from the results of the high-temperature gravimetry. The small oxygen deficiency at this region can be due to the nonstoichiometric composition between A-site and B-site, e.g. formation of A or B site vacancies or substitution of A-site with $\mathrm{Ni}^{2+}$ or $\mathrm{Co}^{2+}$ ions. However, there is still no proof to this assumption and further works are needed to prove it.

\subsection{Oxygen Transport Properties.}

In this part, the sample for the SIMS measurement was prepared at $1573 \mathrm{~K}$ as shown in the Fig 1. The Rietveld analysis was performed to check the XRD pattern of SIMS measurement's sample by TOPAS software (Bruker AXS, Germany). In the analysis, it was assumed the sample has preferred orientation to $<104>$ direction. The GOF (the good of fitness) of the fitting result was around 1.43. It indicates that the sample for SIMS measurement has preferred orientation to $<104>$ direction. To obtain the diffusion coefficient, $D^{*}$, and surface exchange coefficient, $k^{*}$, the ${ }^{18} \mathrm{O}$ concentration profile was obtained from the intensity of ${ }^{18} \mathrm{O}$ signal, $I\left({ }^{18} \mathrm{O}\right)$, in the SIMS line profile normalized to the total of oxygen intensity as described by the following equation:

$$
C\left({ }^{18} \mathrm{O}\right)=I\left({ }^{18} \mathrm{O}\right) /\left(I\left({ }^{18} \mathrm{O}\right)+I\left({ }^{16} \mathrm{O}\right)\right)
$$

the diffusion profile of the sample under various $p\left(\mathrm{O}_{2}\right)$ and various temperature show that the oxygen ratio from the samples were higher than natural abundance of isotope oxygen (0.002) which indicates that the isotope exchange treatments were successful. The ${ }^{16} \mathrm{O}^{-}$and ${ }^{18} \mathrm{O}^{-}$were collected and the diffusion profile was observed for each measurement conditions. 
The solution of Fick's second law for a semi-infinite medium was applied to describe the ${ }^{18} \mathrm{O}$ diffusion profile obtained on the $\mathrm{LaNi}_{0.6} \mathrm{Co}_{0.4} \mathrm{O}_{3-\delta}$. Oxygen diffusion coefficient $D^{*}$ and surface exchange coefficient $k^{*}$ were determined by the following solution given by Crank [10].The solution is described as:

$$
C(180)(\mathrm{x}, \mathrm{t})=C_{0}+\left(C_{g}-C_{0}\right)\left[\operatorname{erfc}\left(\frac{x}{2 \sqrt{D^{*} t}}\right)-\exp \left(\frac{k^{*} x+k^{*} t}{D^{*}}\right) \operatorname{erfc}\left(\frac{x}{2 \sqrt{D^{*} t}}+\frac{k^{*} \sqrt{D^{*} t}}{D^{*}}\right)\right]
$$

where $C\left({ }^{18} \mathrm{O}\right)(\mathrm{x}, \mathrm{t})$ is the experimentally determined ${ }^{18} \mathrm{O}$ isotope ratio at depth $\mathrm{x}, C_{0}$ is the natural abundance of ${ }^{18} \mathrm{O}(0.2 \%), C_{g}$ is the ${ }^{18} \mathrm{O}$ isotope ratio in the gas phase $(99 \%)$, and $\mathrm{t}$ is the annealing time. The $k^{*}$ and $D^{*}$ of $\mathrm{LaNi}_{0.6} \mathrm{Co}_{0.4} \mathrm{O}_{3-\delta}$ are shown in Figs. 5(a) and (b), respectively.

Between isotope oxygen diffusion coefficient and the self-diffusion coefficient of the oxygen, the following relationship is hold:

$$
D^{*}=f D_{\mathrm{o}}
$$

where $f$ is the correlation factor, and $D_{\mathrm{o}}$ is the self-diffusion coefficient of the oxygen. Since $\mathrm{LaNi}_{0.6} \mathrm{Co}_{0.4} \mathrm{O}_{3-\delta} \delta$ has perovskite structure, the correlation factor, f, for oxygen vacancy diffusion is 0.69 based on Compaan and Haven $[12,13]$. The correlation factor, $\mathrm{f}=0.69$, assumes the equal probability of jumps of vacancies in a cubic perovskite, without any cation-vacancy or vacancyvacancy interactions. The relationship between the self-diffusion coefficients of the oxygen with the oxygen vacancy can be described as:

$$
D_{\mathrm{o}}(3-\delta)=D_{\mathrm{v} .} \delta
$$

where $D_{\mathrm{v}}$ is the vacancy diffusion coefficient of $\mathrm{LaNi}_{0.6} \mathrm{Co}_{0.4} \mathrm{O}_{3-\delta}$. In a dilute solution approximation, $D_{\mathrm{v}}$ is constant at a constant temperature. Therefore, the isotope diffusion coefficient must be proportional to $\delta /(3-\delta)$ if the evaluation of $\delta$ is correct. In order to check this relationship, the $D^{*}$ vs. $\mathrm{f}(\delta /(3-\delta))$ was plotted as shown in the Fig. 6 . The $D_{\text {v }}$ of $\mathrm{LaNi}_{0.6} \mathrm{Co}_{4.4 \mathrm{O}_{3-\delta}}$ was determined by the slope of $D^{*}$ vs. $\mathrm{f}(\delta /(3-\delta))$ as $1.4 \times 10^{-5} \pm 1.71810^{-6} \mathrm{~cm}^{2} / \mathrm{s}, 7 \times 10^{-6} \pm 1 \mathrm{x}$ 
$10^{-6} \mathrm{~cm}^{2} / \mathrm{s}$, and $2.2 \times 10^{-6} \pm 8.728 \times 10^{-7} \mathrm{~cm}^{2} / \mathrm{s}$ for $1073 \mathrm{~K}, 973 \mathrm{~K}$, and $873 \mathrm{~K}$, respectively. These values were close to those reported for other perovskite-type oxides [13-15]. Considering the similarity of $D$ v in various perovskite type oxides with similar melting point which have been previously shown by Mizusaki et al [13-15], this result implies that the $D$ v estimated from the $D^{*}$ vs. $\mathrm{f}(\delta /(3-\delta))$ plot are plausible. This, in turn, supports the reliability of $\delta$ determined in this work.

\subsection{Lattice expansion of $\mathrm{LaNi}_{0.6} \mathrm{Co} 0.4 \mathrm{O}_{3-\delta}$}

The $\mathrm{LaNi}_{0.6} \mathrm{Co}_{0.4} \mathrm{O}_{3-\delta} \delta$ powder was measured by $\mathrm{HT}-\mathrm{XRD}$ from room temperature (R.T.) to $1073 \mathrm{~K}$ under $1-10^{-4}$ bar. Rietveld analysis was done on the diffraction patterns of $\mathrm{LaNi}_{0.6} \mathrm{Co}_{0.4 \mathrm{O}_{3}-\delta}$ at R.T using TOPAS software to obtain the information on the structural parameters as shown in Fig. 8. Fig. 9 showed the XRD patterns from R.T to $1073 \mathrm{~K}$ which the sample was in a single phase for the case of $10^{-1}$ bar of $p\left(\mathrm{O}_{2}\right)$. During the measurement, the peak of Pt-Rh was observed. This was caused by the Pt-Rh plate heater where the sample was placed. Part of the heater was exposed during the measurement. Based on this result, it was also assumed that the sample stay at the same phase during the high-temperature gravimetry and coulometric titration measurement. Excluding the Pt-Rh peak, the calculation of lattice parameter of LaNio.6 $\mathrm{Co}_{0.4} \mathrm{O}_{3-\delta} \delta$ could be done to obtain the result shown in Fig 10. The lattice parameters were obtained from the diffraction patterns by Whole Powder Pattern Decomposition with TOPAS software (Bruker AXS, Germany).

The XRD patterns of $\mathrm{LaNi}_{0.6} \mathrm{Co}_{0.4} \mathrm{O}_{3-\delta} \delta$ were indexed as the rombohedral with the $R \overline{3} \mathrm{c}(167)$ space group. In the other side, the Pt-Rh peak was indexed as cubic $F m \overline{3} m$ (225) space group. 
The lattice parameter of $a$ and $c$ of $\mathrm{LaNi}_{0.6} \mathrm{Co}_{0.4} \mathrm{O}_{3-\delta}$ as a function of temperature and $p\left(\mathrm{O}_{2}\right)$ is shown in Fig. 10. The lattice parameter of $\mathrm{LaNi} 0.6 \mathrm{Co} 0.4 \mathrm{O}_{3-\delta}$ sample was independent of $p\left(\mathrm{O}_{2}\right)$ as the lattice parameter remains stable at $1-10^{-4}$ bar $p\left(\mathrm{O}_{2}\right)$. On the other hand, the lattice parameter of $\mathrm{LaNi}_{0.6} \mathrm{Co}_{0.4} \mathrm{O}_{3-\delta} \delta$ sample increased with increasing temperature.

In this case, the lattice parameter could be indicator of oxygen vacancy formation. As the lattice parameter was independence over the $p\left(\mathrm{O}_{2}\right)$, the plateau region of the oxygen nontsotichiometry may have occurred at a high $p\left(\mathrm{O}_{2}\right)$. The thermal expansion under a fixed atmosphere condition is the apparent thermal expansion coefficient $\left(\alpha_{a p}\right)$ which contains the thermally and chemically-induced volume changes. The variation of the lattice parameter of $\mathrm{LaNi}_{0.6} \mathrm{Co}_{0.4} \mathrm{O}_{3-\delta} \delta$ vs temperature was used to calculate the $\alpha_{\mathrm{ap}}$.

For comparison, the lattice parameter of $\mathrm{LaNi}_{0.6} \mathrm{Co}_{0.4} \mathrm{O}_{3-\delta}$ at constant oxygen content $(\delta=$ 0.00115 ) was used to calculate the true thermal expansion coefficient $\left(\alpha_{t}\right)$. Both of $\alpha_{a p}$ and $\alpha_{t}$ are close each other, since the lattice expansion is independent over the $p\left(\mathrm{O}_{2}\right)$. Table 1 shows the $\alpha_{\text {ap }}$ and $\alpha_{t}$ of $\mathrm{LaNi}_{0.6} \mathrm{Co}_{0.4} \mathrm{O}_{3-\delta}$. In this study, the thermal expansion coefficient of $\mathrm{LaNi}_{0.6} \mathrm{Co}_{0.4} \mathrm{O}_{3-\delta}$ was slightly lower than reported by Hjamallrson et al [2]. The average expansion coefficient, $\alpha_{a p-}$ av and $\alpha_{\mathrm{t} \text {-av }}$ were calculated by assuming that cell volume change takes place isotropically.

\section{Conclusions}

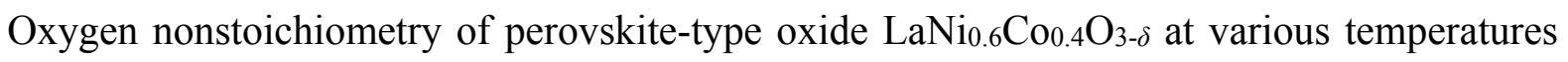
$(873-1073 \mathrm{~K})$ and the $p\left(\mathrm{O}_{2}\right)$ was measured by the high temperature gravimetry and coulometric titration. The oxygen vacancy content was measured by decomposition method at $\mathrm{H}_{2}$ atmoshpere. The $D^{*}$ and $k^{*}$ was obtained by the isotope exchange technique and secondary ion mass spectrometry. 
The delocalized electron model was in good agreement with the experimental data. The $D \mathrm{v}$ which estimated from the $D^{*}$ were close to those reported for other perovskite-type oxides. Considering the similarity of $D \mathrm{v}$ in various perovskite type oxides with similar melting point, this result implies that the $D$ v estimated from the $D^{*}$ vs. $\mathrm{f}(\delta /(3-\delta))$ plot are plausible. Therefore, it supports the reliability of $\delta$ determined in this work.

The result of oxygen nonstoichiometry at high $p\left(\mathrm{O}_{2}\right)\left(1-10^{-4}\right.$ bar $)$ was in good agreement with the lattice expansion which was almost independent over the $p\left(\mathrm{O}_{2}\right)$.

\section{Acknowledgment}

This work was supported by JST, Japan, as part of "Phase Interface Science for Highly Efficient Energy Utilization" project in strategic basic research program, CREST.

\section{References}

[1] M. Oishi, K. Yashiro, J. O. Hong, Y. Nigara, T. Kawada, J. Mizusaki, Solid State Ionics, 178, (2007) 307 .

[2] P. Hjalmarsson, M. Sogaard, A. Hagen, and M. Mogensen, Solid State Ionics, 179, (2008) 636-646.

[3] V.V. Kharton, A.P. Viskup, E.N. Naumovich, and V.N. Tikhonovich, Material Research Bulletin, 34, (1999) 1311.

[4] P. Hjalmarsson, and M. Mogensen, J. Power Sources, 196 (2011) 53-60.

[5] M. HHrovat, and N. Katasarakis, K. Reichmann, S. Bernik, D. Kuscer, J. Holc, Solid State Ionics, 83 (1996) 99-105.

[6] J. Mizusaki, Y. Mima, S. Yamauchi, and K. Fueki, J. Solid State Chemistry, 80 (1989) 108. 
[7] S. Onuuma, K. Yashiro, S. Miyoshi, A. Kaimai, H. Matsumoto, Y. Nigara, T. Kawada, J. Mizusaki, K. Kawamura, N. Sakai, and H. Yokokawa, Solid State Ionics, 174 (2004) 287.

[8] J. Mizusaki, M. Hasegawa, K. Yashiro, H. Matsumoto, and T. Kawada, Solid State Ionics, $177(2006) 1925$.

[9] J. Mizusaki, S. Yamauchi, K. Fueki, and A. Ishikawa, Solid State Ionics, 12 (1984) 119.

[10] M. Kuhn, Y. Fukuda, S. Hashimoto, K. Sato, K. Yashiro, and J. Mizusaki, Journal of The Electrochemistry Society, 160 (1) (2013) F37.

[11] J. Crank, The Mathematics of Diffusion, 2nd ed., Clarendon Press, Oxford, 1975.

[12] K. Compaan, and Y. Haven, Trans. Faraday Soc. 52 (1956) 786.

[13] T. Ishigaki, S. Yamauchi, K. Kishio, J. Mizusaki, and K. Fueki, Journal of Solid State Chemistry, 73 (1988) 184.

[14] J. Mizusaki, I. Yasuda, J. Shimoyama, S. Yamauchi, K. Fueki, Journal of Electrochemistry Society, 140 (1993) 467-471.

[15] H. Kudo, K. Yashiro, S. Hashimoto, K. Amezawa, T. Kawada, Solid State Ionics, 262 (2014) 699. 
Table 1. Apparent and true thermal expansion coefficient of $\mathrm{LaNi}_{0.6} \mathrm{Co}_{0.4} \mathrm{O}_{3-\delta}$.

\begin{tabular}{cccccc}
\hline $\boldsymbol{\alpha}_{\text {ap-a }} / \mathbf{K}^{-1}$ & $\boldsymbol{\alpha}_{\text {ap-c }} / \mathbf{K}^{-1}$ & $\boldsymbol{\alpha}_{\text {ap-av }} / \mathbf{K}^{-1}$ & $\boldsymbol{\alpha}_{\mathrm{t}-\mathbf{a}} / \mathbf{K}^{-\mathbf{1}}$ & $\boldsymbol{\alpha}_{\mathrm{t}-\mathrm{c}} / \mathbf{K}^{-\mathbf{1}}$ & $\boldsymbol{\alpha}_{\mathrm{t}-\mathrm{av}} / \mathbf{K}^{-\mathbf{1}}$ \\
\hline $9.95 \times 10^{-6}$ & $2.27 \times 10^{-5}$ & $16.3 \times 10^{-6}$ & $9.32 \times 10^{-6}$ & $2.25 \times 10^{-5}$ & $16 \times 10^{-6}$ \\
\hline
\end{tabular}

Figure Caption

Figure 1 XRD patterns of $\mathrm{LaNi}_{0.6} \mathrm{Co}_{0.4} \mathrm{O}_{3-\delta}$ at room temperature before and after reduction in $100 \% \mathrm{H}_{2}$ and sample which prepared at $1573 \mathrm{~K}$.

Figure 2 The Oxygen nonstoichiometry of $\mathrm{LaNi}_{0.6} \mathrm{Co}_{0.4} \mathrm{O}_{3-\delta}$ as function of temperature and $p\left(\mathrm{O}_{2}\right)$.

The dashed line shows the delocalized model which fitted to the experimental data.

Figure 3 Variation of the difference in (a) partial molar enthalpy and (b) partial molar entropy of the oxygen vacancy formation in $\mathrm{LaNi} 0.6 \mathrm{Co}_{0.4} \mathrm{O}_{3-\delta}$ with oxygen nonstoichiometry.

Figure 4 Relationship between the ${ }^{18} \mathrm{O} /\left({ }^{16} \mathrm{O}+{ }^{18} \mathrm{O}\right)$ and depth from the sample surface. The oxygen isotope $\left({ }^{18} \mathrm{O}\right)$ exchange conditions were $873 \mathrm{~K}$ at (a) $p\left(\mathrm{O}_{2}\right)=10^{-2}$ bar and (b) $p\left(\mathrm{O}_{2}\right)=$ $10^{-3}$ bar for $30 \mathrm{~min}$.

Figure 5 The diffusivity $\left(D^{*}\right)$ of the $\mathrm{LaNi}_{0.6} \mathrm{Co}_{0.4} \mathrm{O}_{3-\delta}$ (a) and surface exchange rate of $\mathrm{LaNi}_{0.6} \mathrm{Co}_{0.4} \mathrm{O}_{3-\delta}(\mathrm{b})$ at various temperature and $p\left(\mathrm{O}_{2}\right)$.

Figure 6 The $D^{*}$ vs. $\mathrm{f}(\delta /(3-\delta))$ of $\mathrm{LaNi}_{0.6} \mathrm{Co}_{0.4} \mathrm{O}_{3-\delta}$. The $D_{\mathrm{v}}$ is calculated from the slope of $D^{*}$ vs. $f(\delta /(3-\delta))$

Figure 7 The vacancy diffusion, $D_{\mathrm{v}}$, of several perovskite-type oxide.

Figure 8 The result of Rietveld analysis on XRD pattern of $\mathrm{LaNi} 0.6 \mathrm{Co}_{.4} \mathrm{O}_{3}-\delta$ at room temperature $R_{\mathrm{wp}}=5.43 \%, R_{\mathrm{p}}=4.2 \%$ and $\mathrm{GOF}=1.21$ 
Figure 9 The XRD pattern under $10^{-1}$ bar $p\left(\mathrm{O}_{2}\right)$. The result showed that the sample was in a single phase in the range of the XRD measurement. The closed symbol (•) is the Pt peak which came from the platinum heater of HT-XRD.

Figure 10 Lattice parameter and cell volume of $\mathrm{LaNi}_{0.6} \mathrm{Co}_{0.4} \mathrm{O}_{3-\delta}$ as function of temperature and $p\left(\mathrm{O}_{2}\right)$; (a) a vs. $\log p\left(\mathrm{O}_{2}\right)$ and (b) $c$ vs. $p\left(\mathrm{O}_{2}\right)$ (c) cell volume vs. $p\left(\mathrm{O}_{2}\right)$.

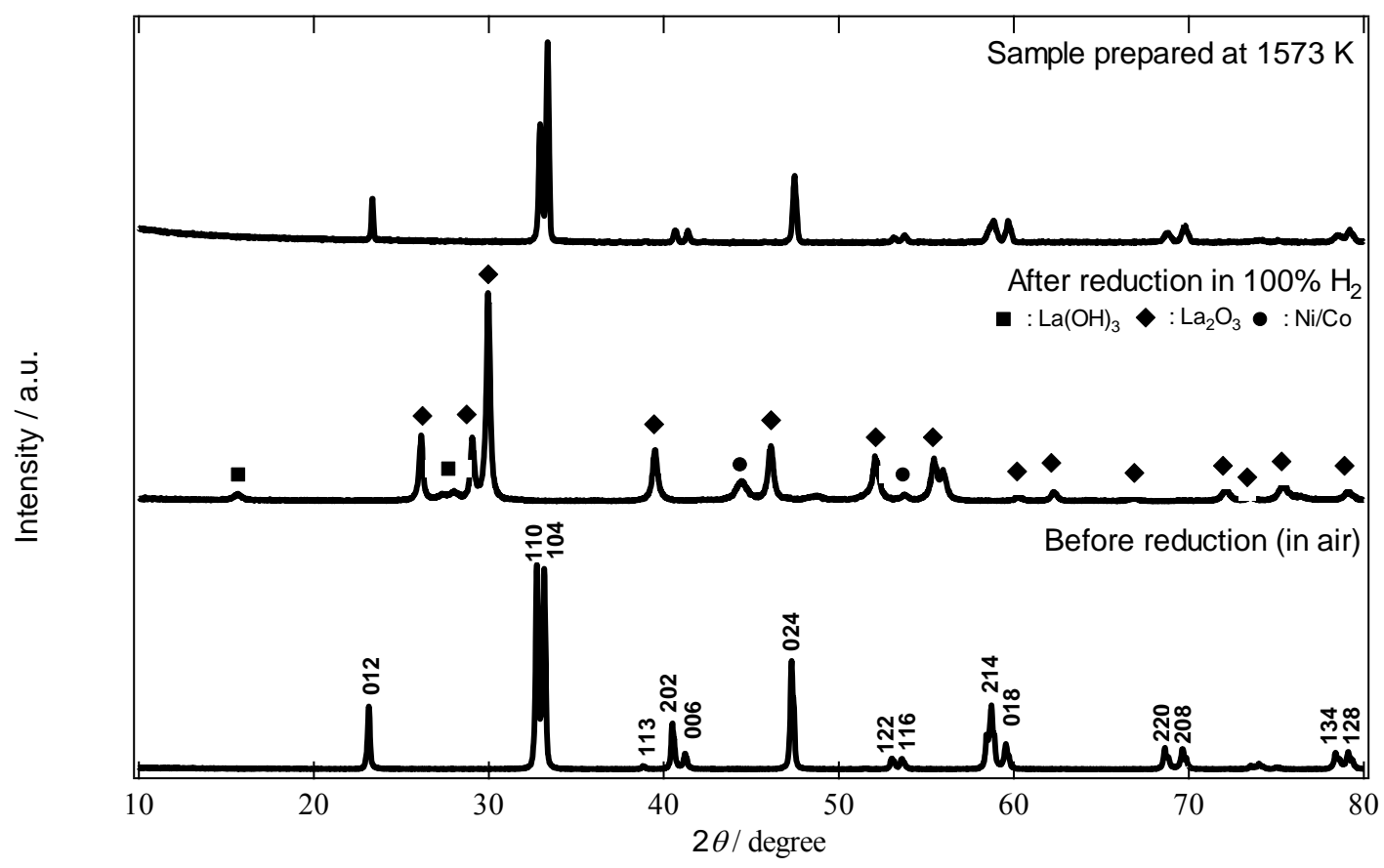

Figure 1. 


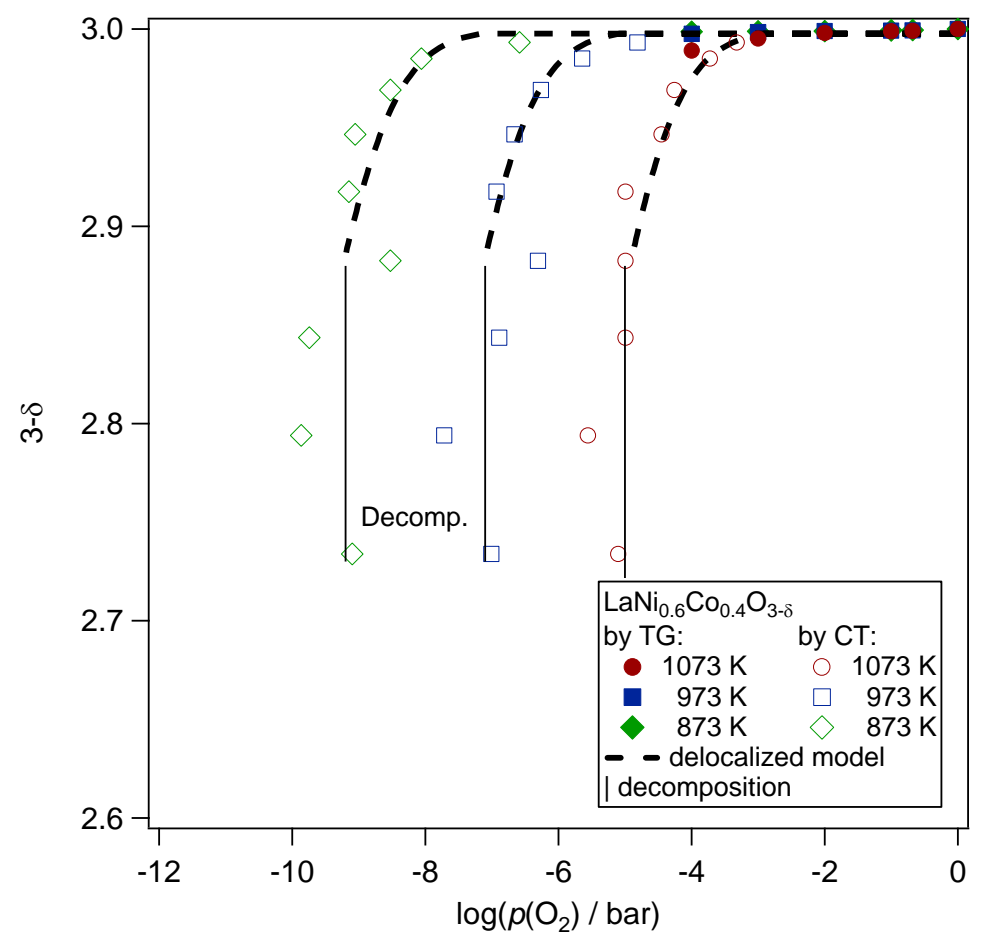

Figure 2. 


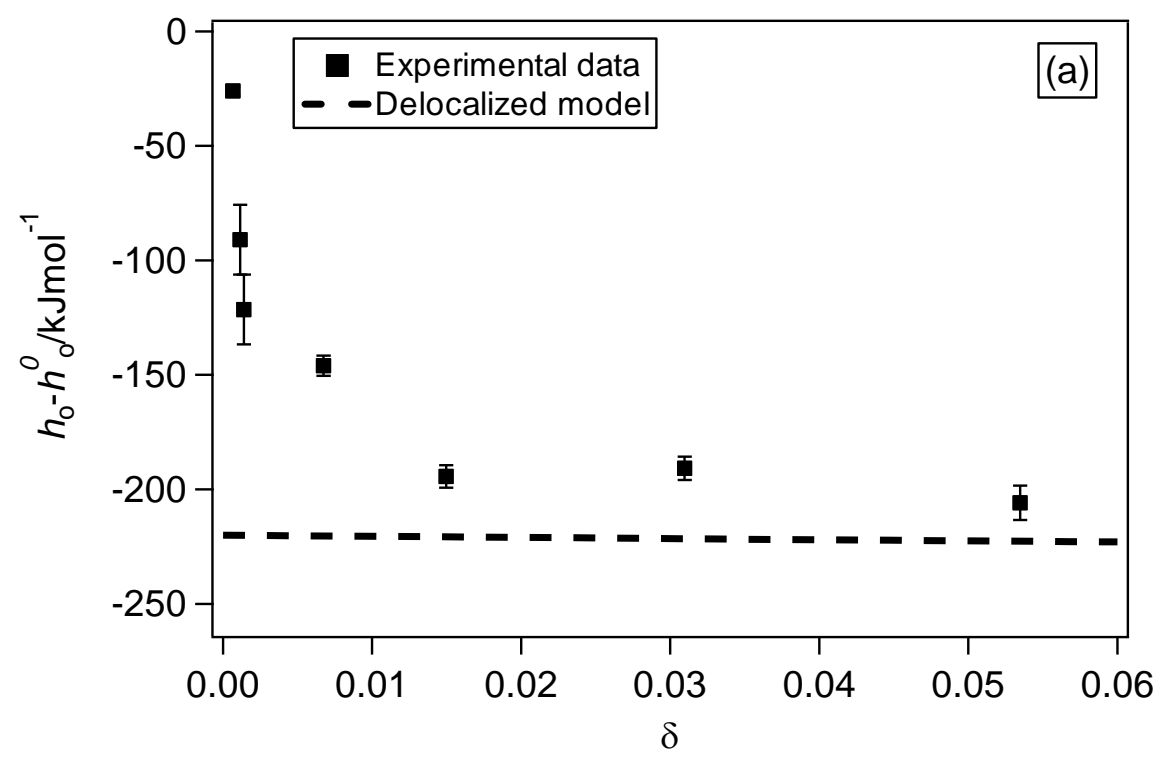

(a)

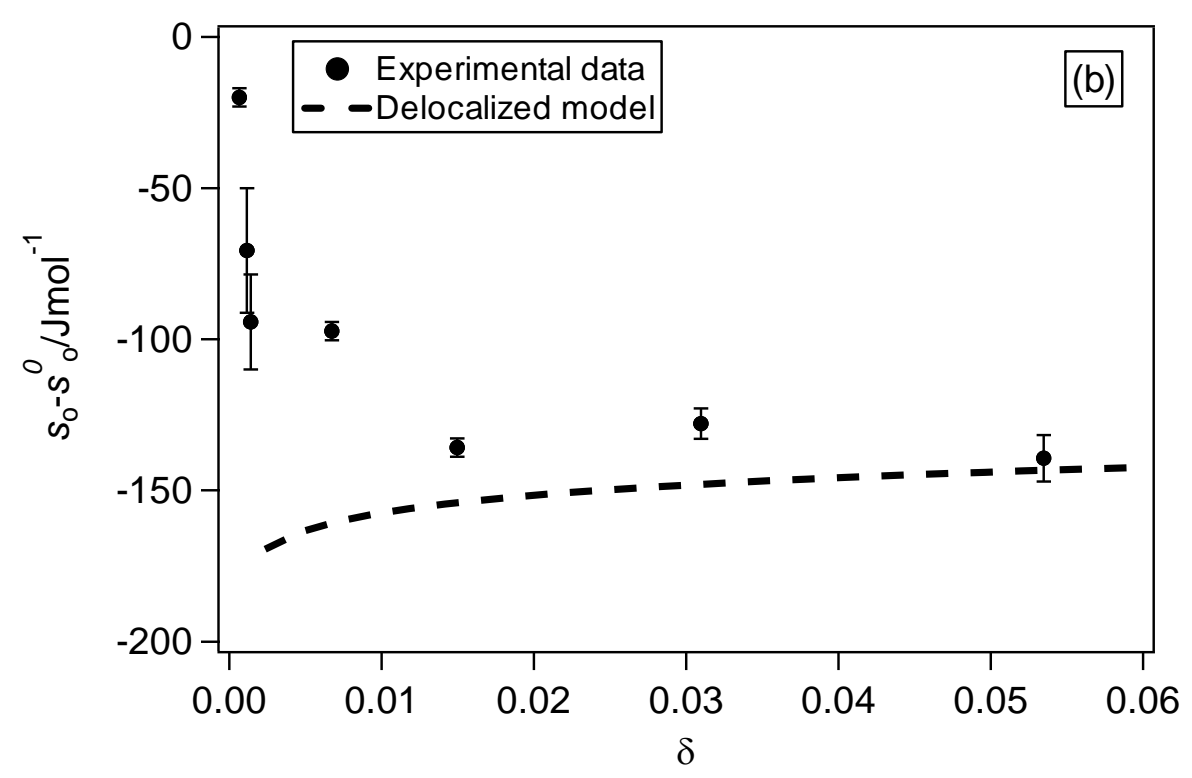

(b)

Figure 3. 


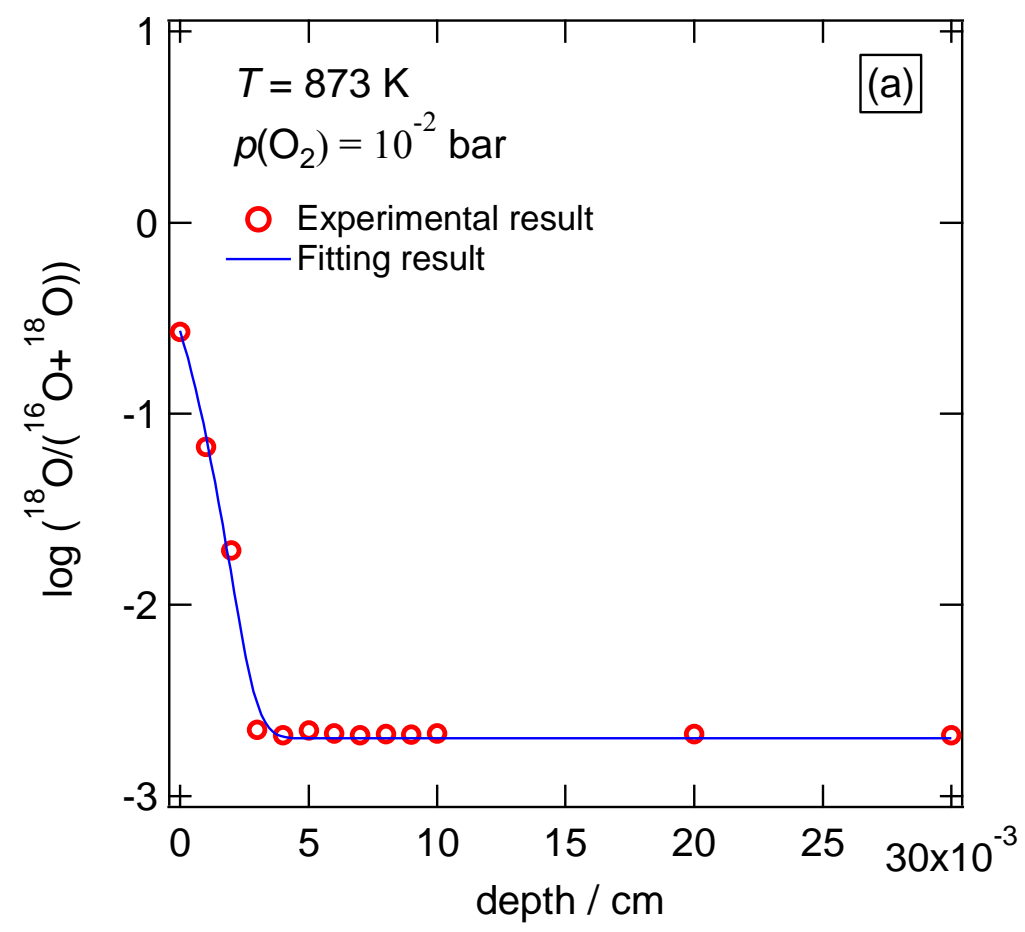

(a)

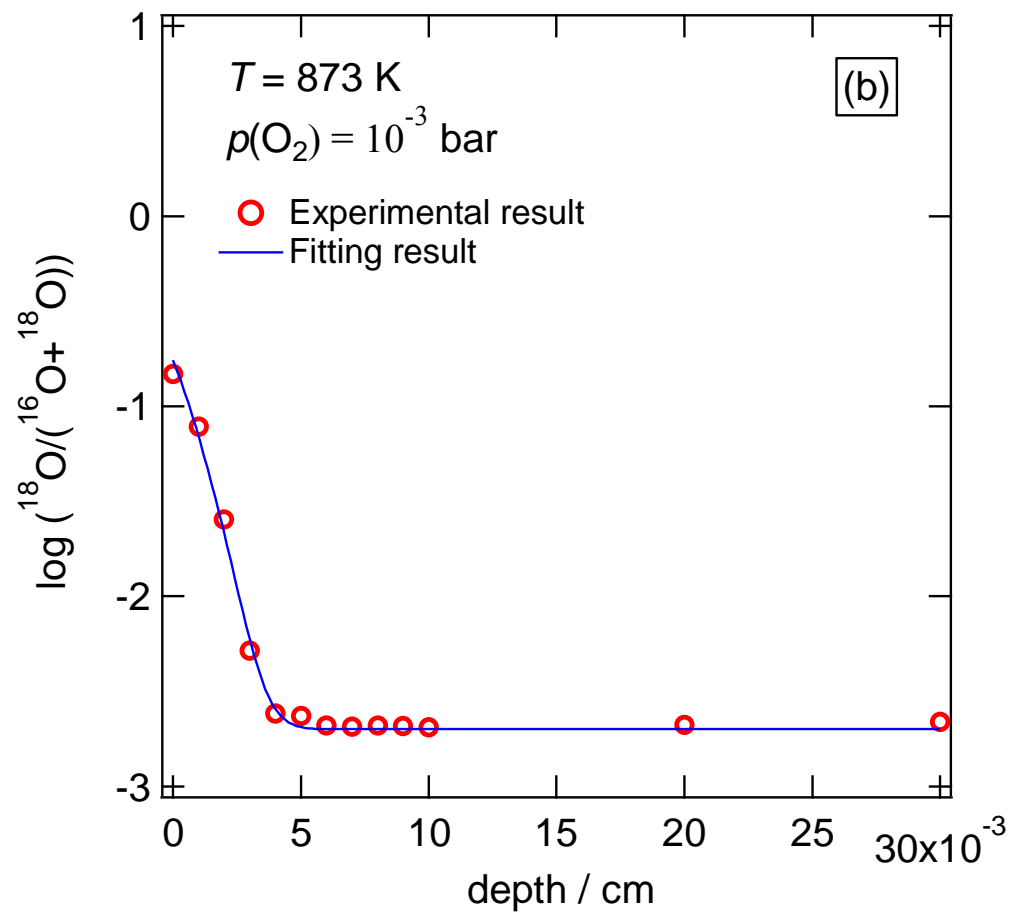

(b)

Figure 4. 


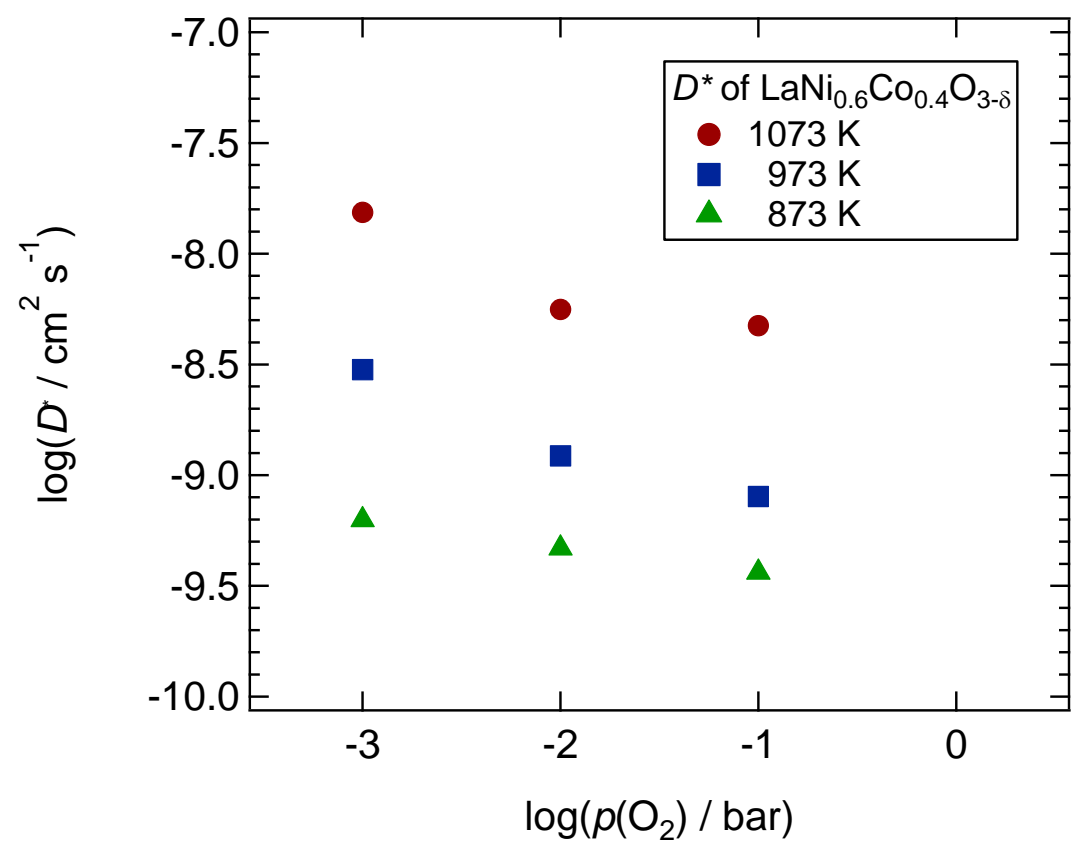

(a)

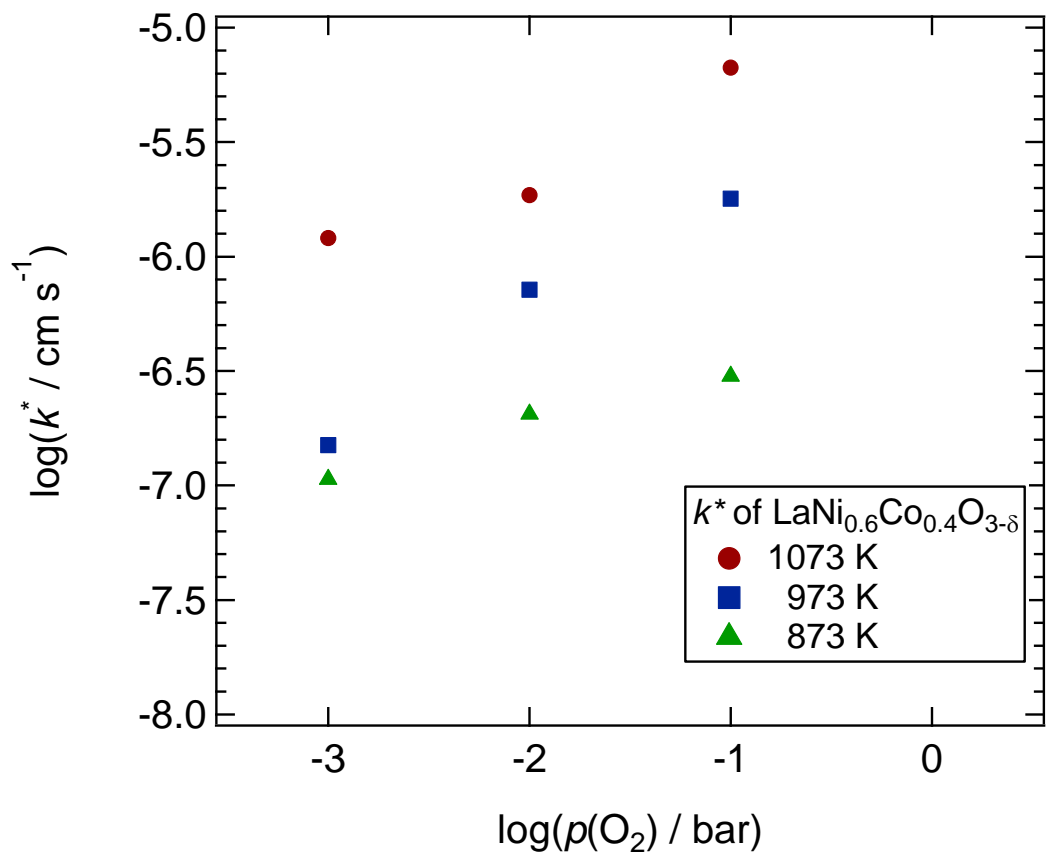

(b)

Figure 5. 


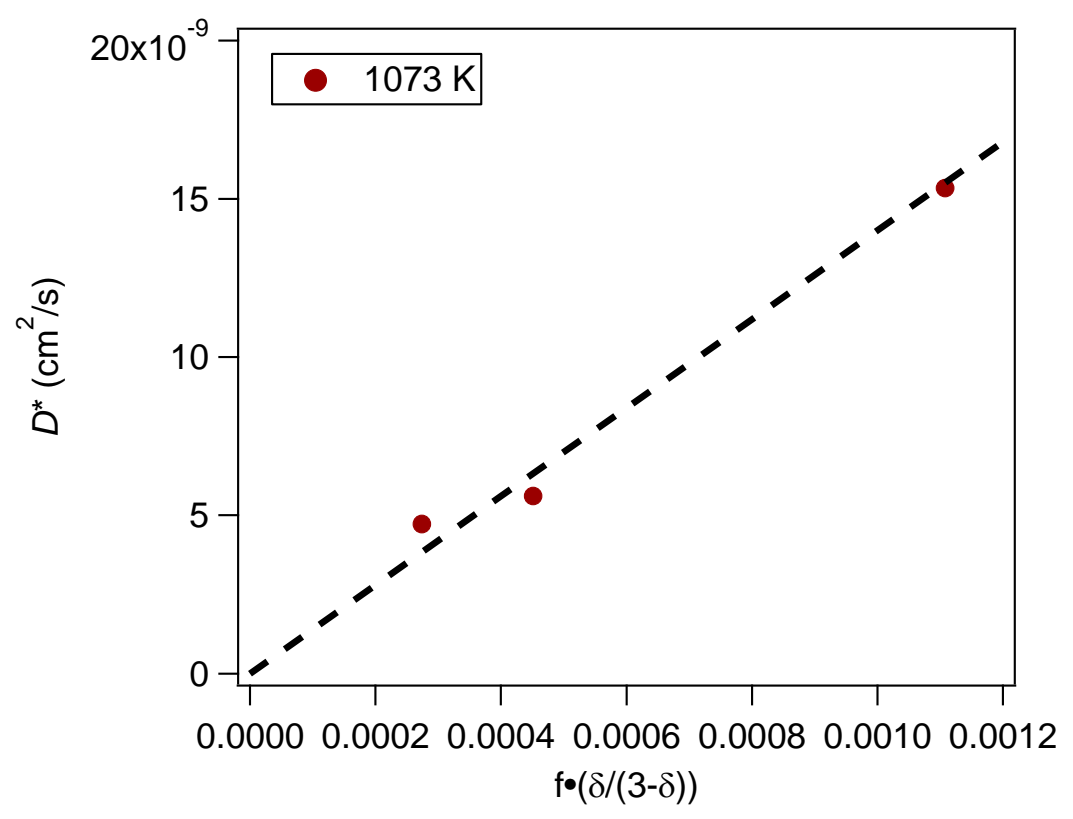

(a)

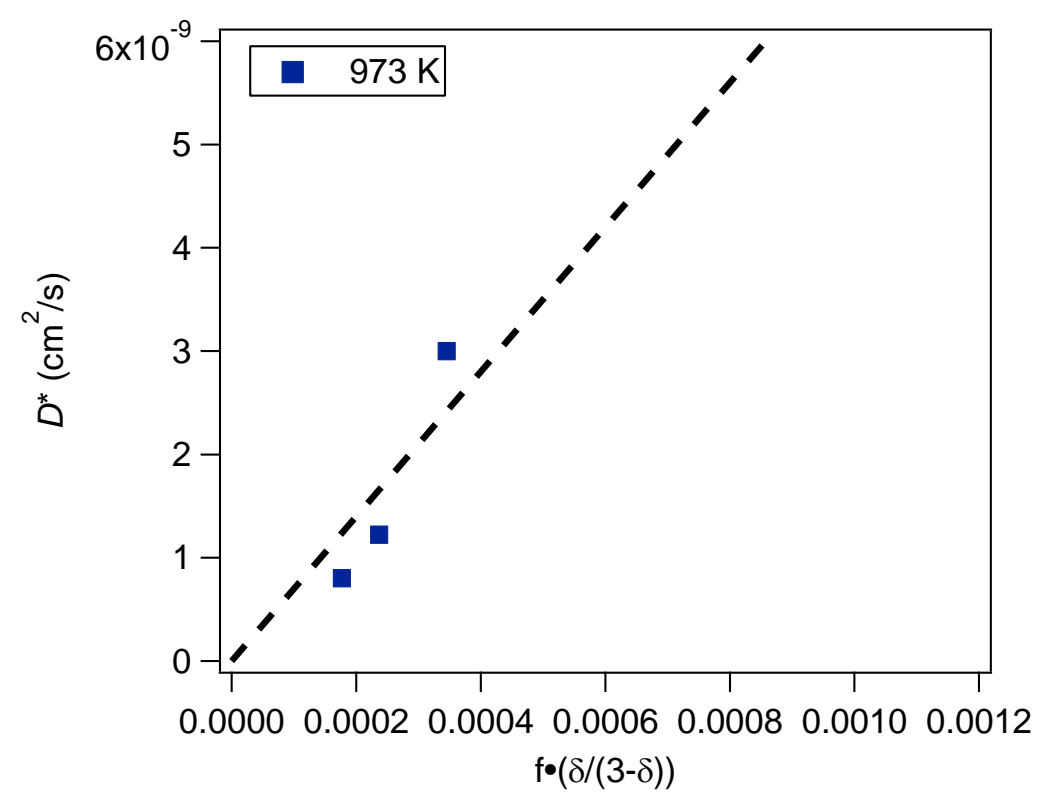

(b) 


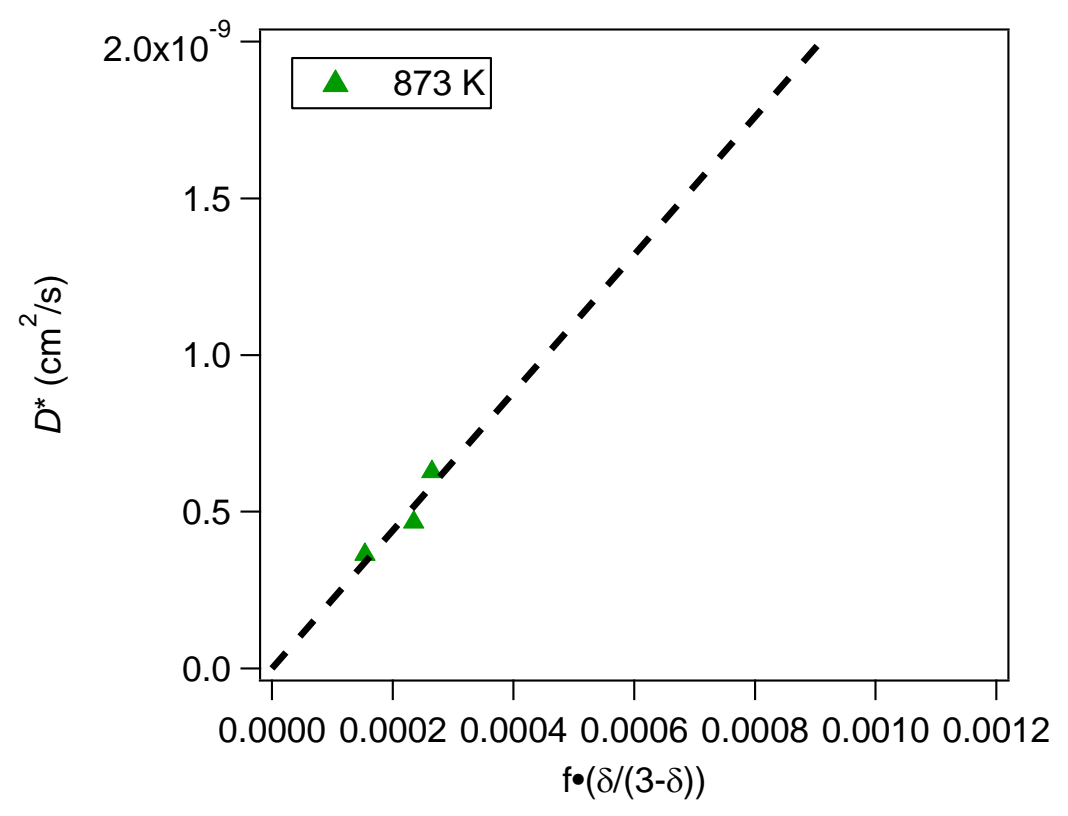

(c)

Figure 6 


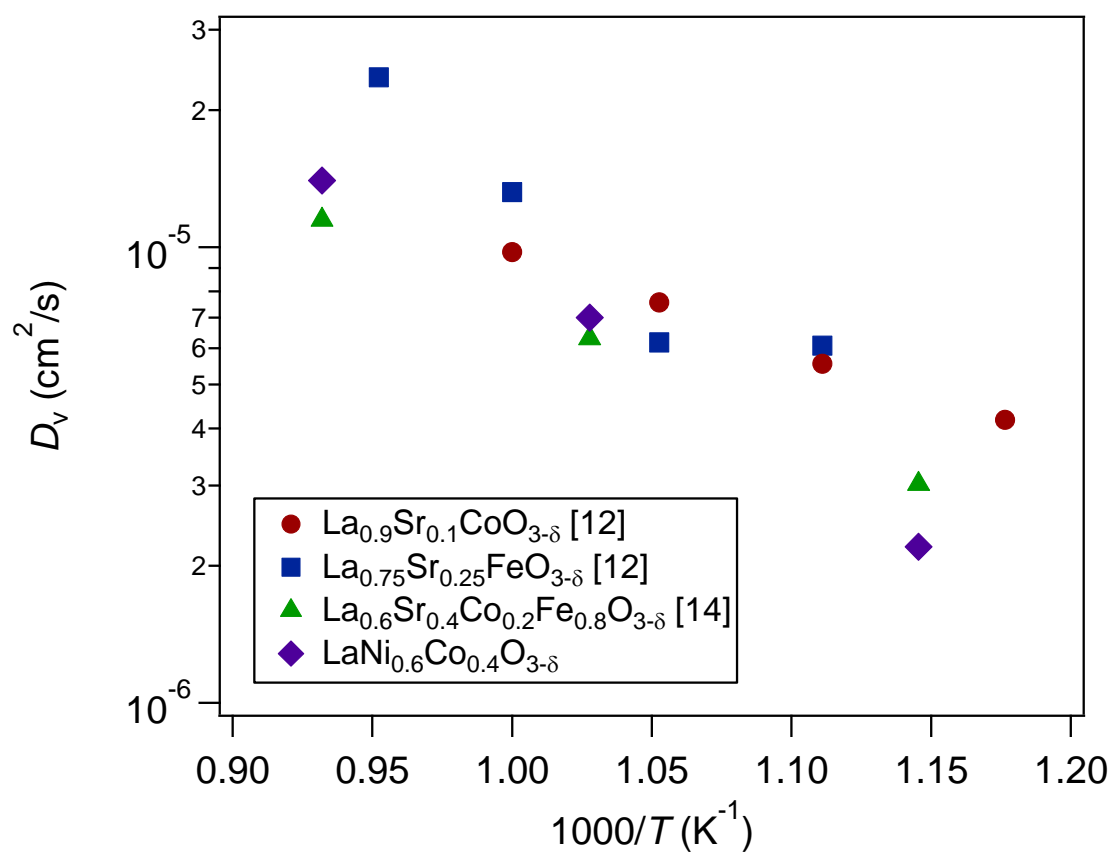

Figure 7.

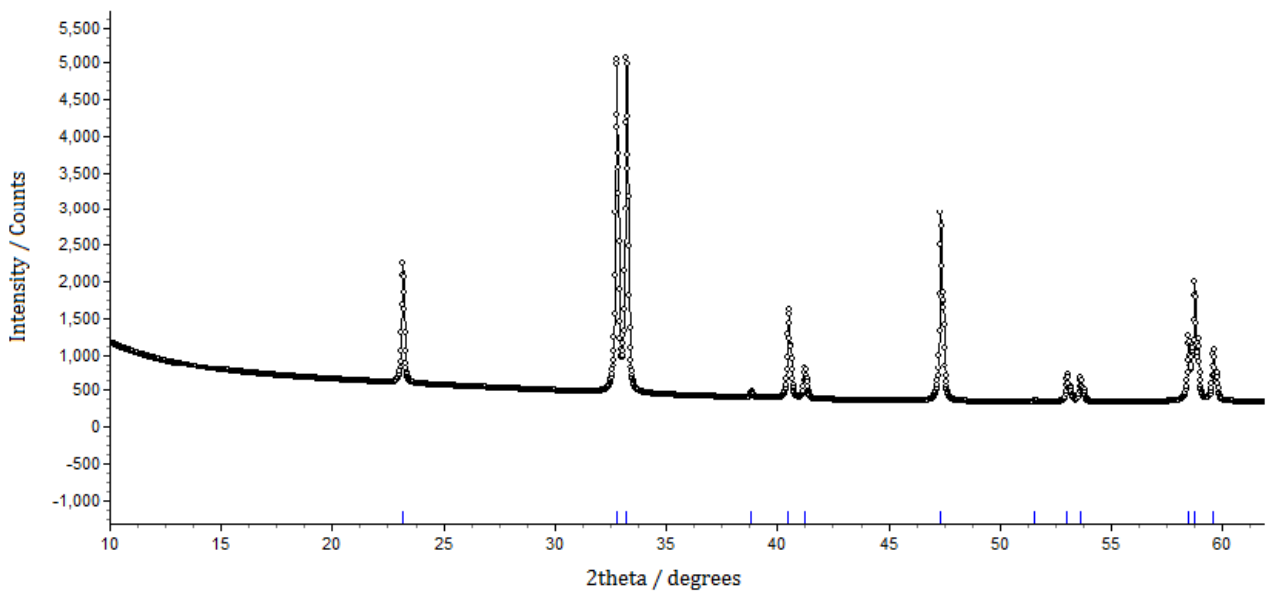

Figure 8. 


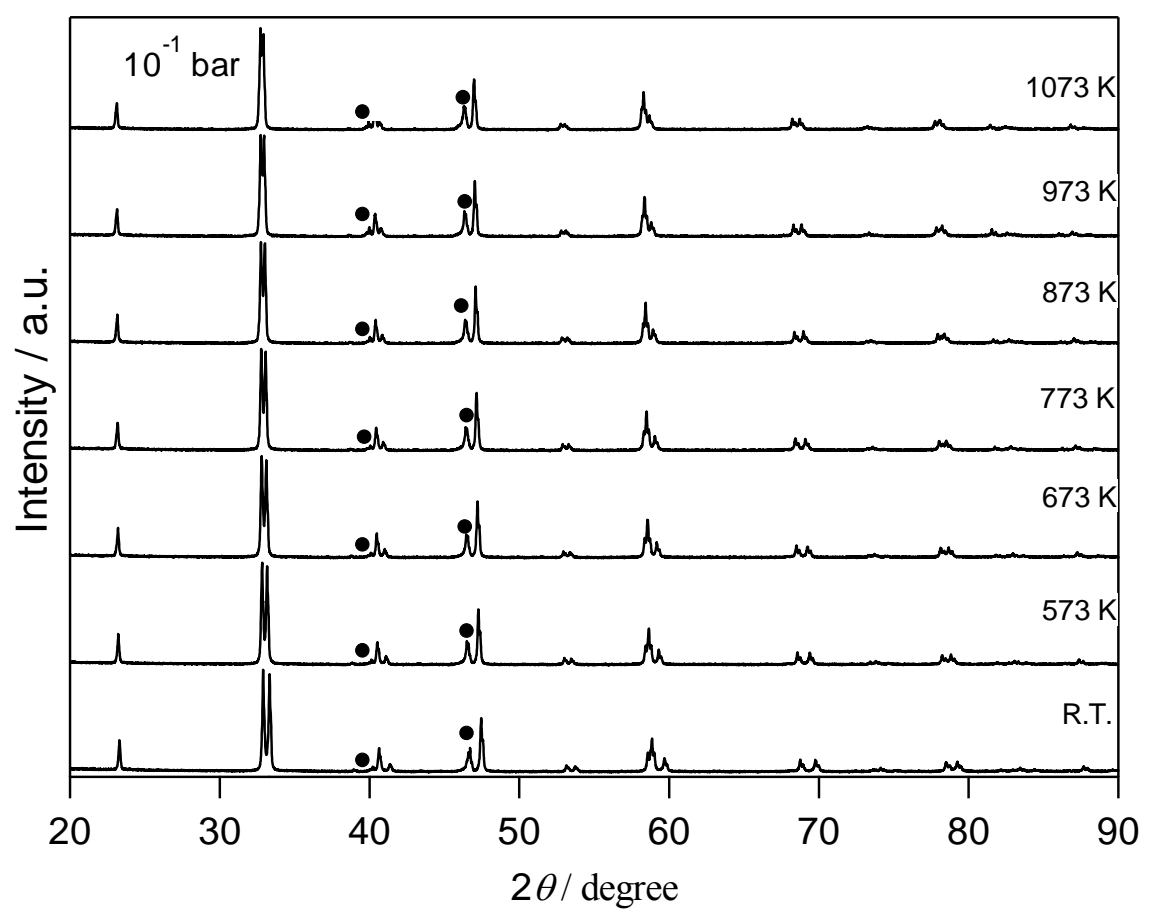

Figure 9.

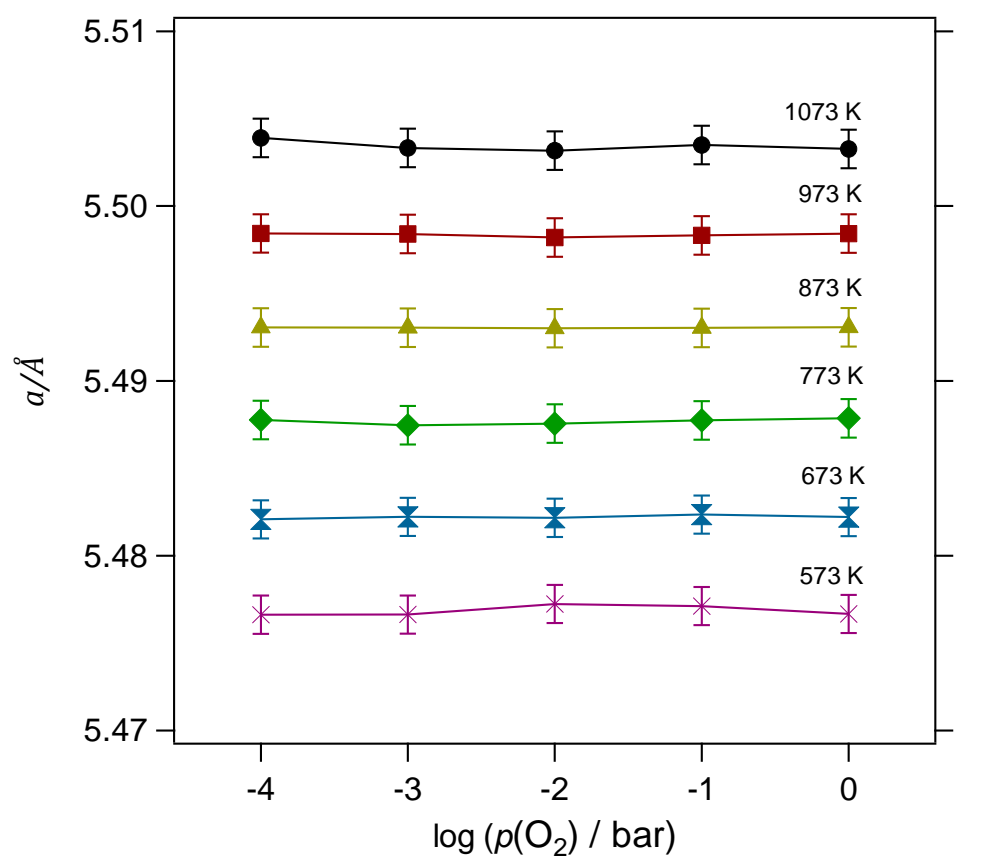

(a) 


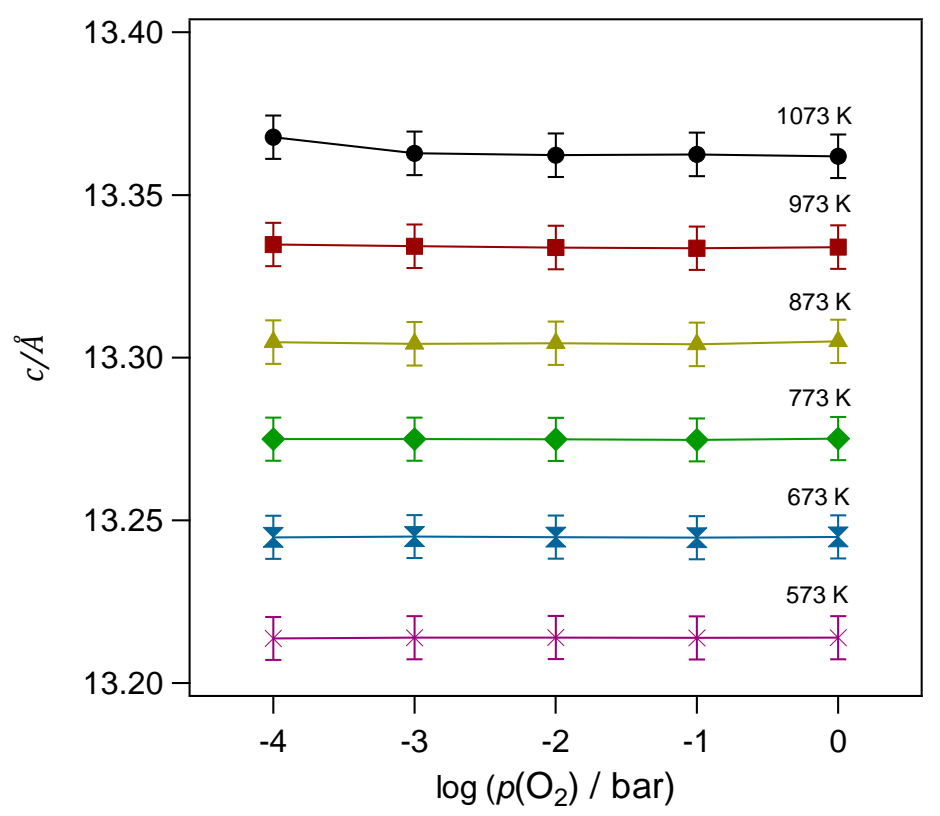

(b)

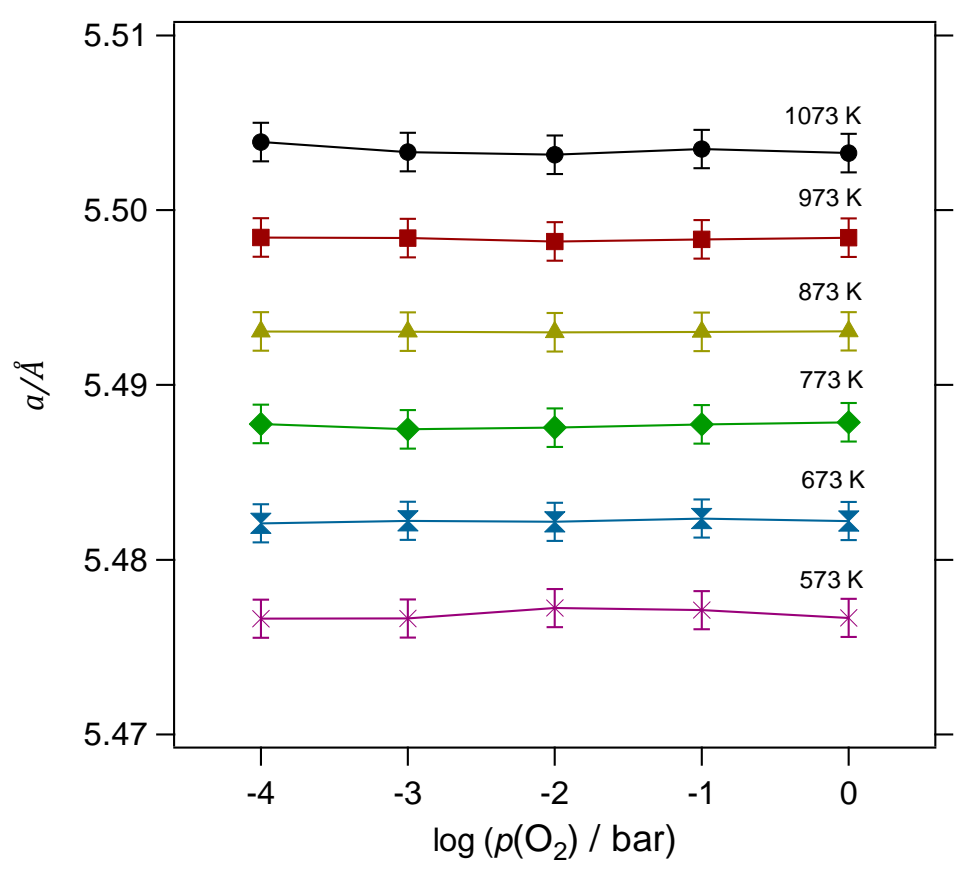

(c)

Figure 10 